\title{
ANÁLISE SOBRE A INTERFERÊNCIA ANTRÓPICA NA ORIGEM DOS CAMPOS DO NÚCLEO CURUCUTU, PARQUE ESTADUAL DA SERRA DO MAR, SÃO PAULO
}

\section{Ricardo José Francischetti Garcia}

Biólogo, doutor pelo Instituto de Biociências da USP, lotado no Herbário Municipal do Departamento de Parques e Áreas Verdes, Prefeitura do Município de São Paulo. E-mail: rigarcia@estado.com.br

José Rubens Pirani

Biólogo, professor titular do

Departamento de Botânica do Instituto de Biociências da Universidade de São Paulo.

E-mail: irpirani@ib.usp.br

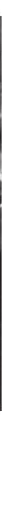




\title{
RESUMO
}

Com o objetivo de investigar a importância da interferência antrópica na origem dos campos situados junto da crista da Serra do Mar, no município de São Paulo, realizou-se levantamento em diversas fontes de dados históricos que abrangessem a região, especialmente sob o aspecto de atividades econômicas, expansão urbana e vias de comunicação, como possíveis fatores de impacto sobre a vegetação. Verificou-se que a atividade de carvoarias, em meados do século $X X$, constituiu-se no principal fator de degradação local. Essa atividade, contudo, não é suficiente para explicar a ocorrência de campos no local, embora, possivelmente, tenha retardado a substituição natural dos campos por matas. Discute-se a importância da flora do Núcleo Curucutu para medidas de resgate histórico da flora do município de São Paulo.

Palavras-chave: Serra do Mar, vegetação campestre, São Paulo, história, flora.

\begin{abstract}
Aiming to investigate the importance of human interference on the origin of grasslands on crests of Serra do Mar in the municipality of São Paulo, a survey was made using several types of historical records. The latter dealt with the region, particularly with features of economic activities, urban expansion and communicating paths as possible factors impacting the vegetation. Timber felling for charcoal production in the midst of the $20^{\text {th }}$ century was the main factor for local degradation. However, such activity was not strong enough to account for the total occurrence of local grasslands. A possibility is admitted, however, that charcoal production has delayed the natural grassland replacement for rain forest. The Curucutu flora is discussed in connection with its importance as means for the historical recovery of the flora of São Paulo municipality.
\end{abstract}

Key words: Serra do Mar, grasslands, São Paulo, history, flora. 


\section{ANÁLISE SOBRE A INTERFERÊNCIA ANTRÓPICA NA ORIGEM DOS CAMPOS DO NÚCLEO CURUCUTU, PARQUE ESTADUAL DA SERRA DO MAR, SÃO PAULO}

\section{Introdução}

A ocorrência de vegetação campestre em região de domínio florestal tem gerado alguma controvérsia sobre a gênese desta formação na bacia de São Paulo. Em estudo geográfico sobre o bairro de Pinheiros, Azevedo (1963) considerava duas hipóteses, igualmente aceitáveis, para a existência dos "campos de Piratininga" encontrados na época da colonização: ou seriam resultantes da ação antrópica indígena, com o uso do fogo e a prática da agricultura itinerante, acentuados pela concentração populacional nessa área, ou ainda, a preexistência da vegetação campestre, no local, teria sido um fator para a escolha desse sítio na fixação da população.

Analisando o levantamento bibliográfico sobre estudos com vegetação para o estado de São Paulo e o Brasil, encontram-se considerações ora a favor da primeira alternativa, ora da segunda. Assim, a favor da primeira alternativa e sua continuidade histórica (colonização portuguesa em diante) ressaltam-se a conclusão de Joly (1950) para a origem dos "campos de Butantã" e Coutinho (1962) para os campos de Paranapiacaba. O mapa de Hueck (1956) também desconsidera a existência de campos como vegetação original na Serra do Mar.

A favor da segunda alternativa destaca-se Löfgren (1898), que reconhecia como naturais os campos atrás da crista da Serra do Mar, a partir de sua flora especial e condições climáticas diferenciadas. Também Wettstein (1970) distinguia as savanas e os "campos molhados" dentre os tipos de vegetação nativa, mas considerava que as savanas estariam ampliando sua extensão na periferia da capital paulista pela derrubada das matas. Hoehne (1925) ressaltava como naturais os "campos higrófilos" de Paranapiacaba, devido à flora peculiar.

Levantamento florístico realizado no Núcleo Curucutu, Parque Estadual da Serra do Mar, extremo sul do município de São Paulo (Mapa 1), bem como a análise das condições climáticas e de solo, considerações paleoambientais e análises comparativas com outros campos brasileiros, apresentaram fortes evidências de a vegetação em questão tratar-se de campo natural (Foto 1), de grande similaridade com os campos de altitude típicos (GARCIA, 2003; GARCIA e PIRANI). 


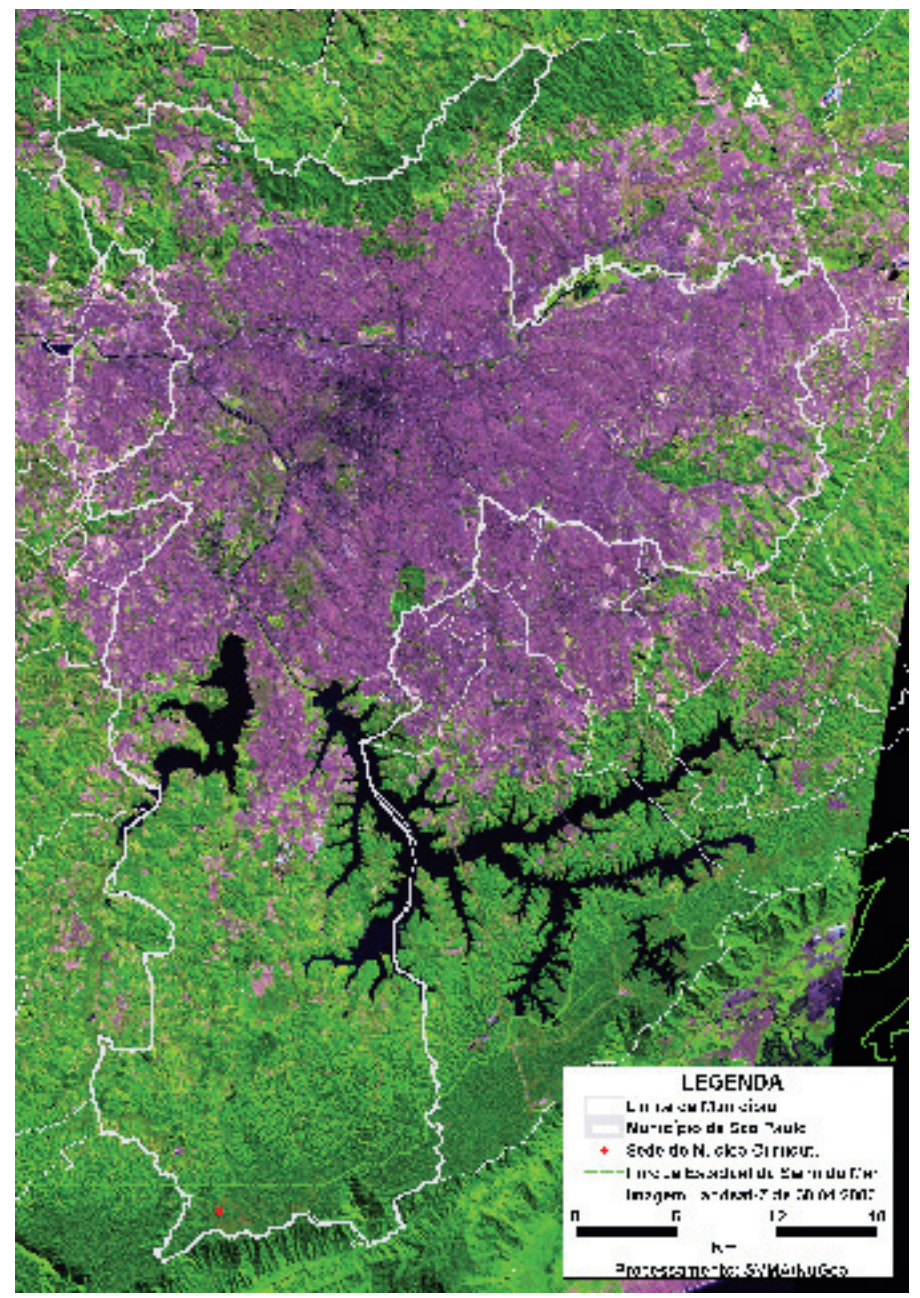

Mapa 1: Localização do trecho do Parque Estadual da Serra do Mar no município de São Paulo e a sede do Núcleo Curucutu. Legenda: lilás a roxo: área edificada; verde: áreas florestadas ou densamente arborizadas; azul escuro: corpos d'água; rosa acinzentado: campo. Fonte: Imagem de satélite Landsat 7, composição das bandas 3 , 4 e 5, de cena de 30.04.2000, preparada pelo arquiteto

Flávio L. Fatigati (Núcleo de Geoprocessamento, SVMA, PMSP)

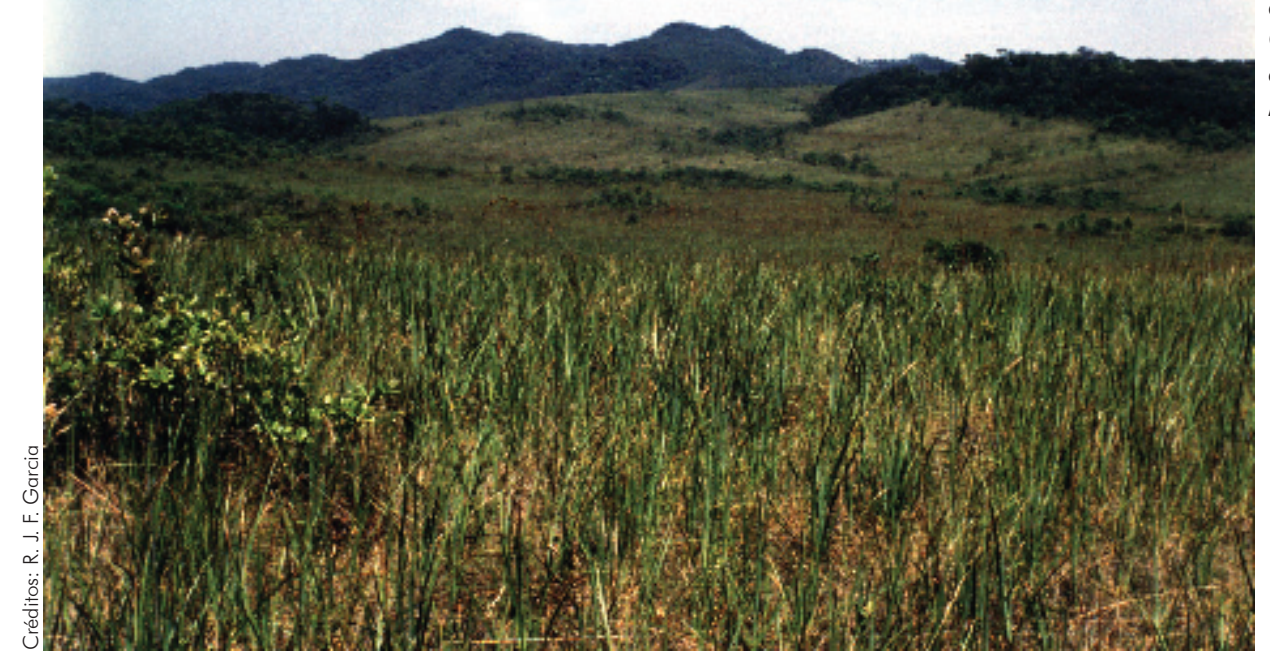

Foto 1: Aspecto geral dos campos do Núcleo Curucutu. Ao fundo, crista da Serra do Mar 
Considerando que flora e vegetação podem estar refletindo interferência antrópica, o presente trabalho buscou levantar elementos para discutir a importância dessa interferência na origem e manutenção dessa vegetação no Núcleo Curucutu. Foi realizado um levantamento de informações históricas deste núcleo e da região sul do município de São Paulo, procurando resgatar elementos sobre a paisagem (se campestre ou florestal) e as possíveis ações as quais propiciassem alterações na mesma, como extrativismo, estradas, práticas agrícolas, entre outras.

\section{Toponímia}

O topônimo "Curucutu" é encontrado para a "Reserva Florestal do Estado" em mapas da Emplasa e IBGE, mas também como bairro rural em São Bernardo do Campo e na aldeia dos índios guarani, na região da Barragem (também como "Krucutu"). A origem do nome, segundo funcionários do núcleo, é onomatopéica, em referência ao piado de uma coruja da região.

Mapa 2:

Localização de acidentes geográficos, localidades,

bairros e áreas indígenas citados no texto; das áreas campestres, segundo

documentaçãa fotográfica, histórica e de exsicatas; dos herbários públicos no município de São Paulo; e do caminho de Santo Amaro a ltanhaém, baseado em Zenha (1977)

Fonte: Elaboração de R. J. F. Garcia preparado pelo arquiteto Flávio L. Fatigati (Núcleo de Geoprocessamento, SVMA, PMSP)

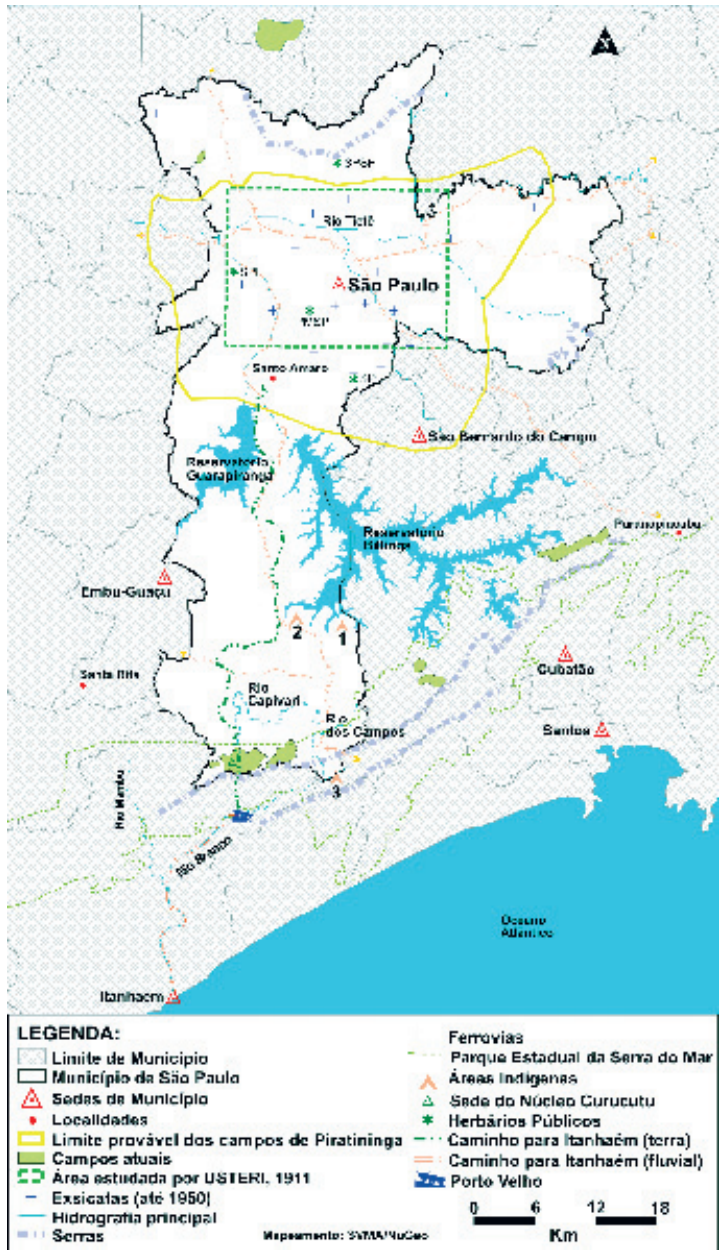

Evidência de campos no alto da Serra do Mar, analisandose a toponímia da região, é sugerida pela designação "rio dos Campos" para um curso d'água, afluente do rio Capivari. Também é interessante notar que "Paranapiacaba" é topônimo tupi-guarani, o qual significa "local de onde se avista o mar", sendo plausível tratarse de locais com vegetação aberta, não apenas clareiras na mata. Próxima a Paranapiacaba encontra-se a localidade "Campo Grande" (Mapa 2).

\section{A População Indígena Local}

Quanto às populações indígenas presentes na região (Tabela 1), cabe destacar sua origem alóctone e relativamente recente (menos de um século), conforme estudo de Ladeira (1984). 


\section{Tabela 1: Algumas características das áreas indígenas guarani encontradas na região próxima ao Núcleo Curucutu}

\begin{tabular}{|l|c|c|c|c|}
\hline \multicolumn{1}{|c|}{$\begin{array}{c}\text { Aldeia / grupo } \\
\text { (n. no Mapa 2) }\end{array}$} & Local & $\begin{array}{c}\text { Área } \\
\text { (alqueires) }\end{array}$ & $\begin{array}{c}\text { Número de } \\
\text { famílias }\end{array}$ & $\begin{array}{c}\text { Tempo de } \\
\text { permanên- } \\
\text { cia no local }\end{array}$ \\
\hline 1. Krucutu & Barragem, São Paulo - SP & 18 & 2 & 8 \\
\hline 2. Morro da Saudade & Barragem, São Paulo - SP & 8 & 35 & 20 \\
\hline 3. Rio Branco & $\begin{array}{c}\text { Parque Estadual da Serra } \\
\text { do Mar, Itanhaém - SP }\end{array}$ & 350 & 10 & $>80$ \\
\hline
\end{tabular}

Fonte: LADEIRA, Maria Inês Martins. Índios no estado de São Paulo: Resistência e transfiguração, 1984

A autora ressaltou que todos esses grupos migraram a partir do Sul do país, sendo esta mobilidade característica dos mesmos. A localização dessas aldeias foi considerada estratégica para as populações locais se deslocarem até a Serra do Mar, em busca de recursos alimentares (complementando o cultivo de pequenas roças em suas aldeias), medicinais e para confecção de artesanato (vendidos à população "branca", no litoral ou em Santo Amaro). Essa rede de locais, à qual se relaciona uma área no Jaraguá, também serve de base de apoio a outros grupos guarani em migração do Sul para Norte. Assim, há uma circulação regular dessa população, utilizando trilha a partir da Barragem até o rio Branco, sem, contudo, passar pela área campestre do Núcleo Curucutu, como também informam os funcionários deste.

Parece razoável supor que os campos do Núcleo Curucutu não tenham, para essas populações, importância fundamental na obtenção de recursos, visto que:

- Em quase 100 anos de ocorrência na região, não se instalaram nas áreas campestres (preferiram as matas e bordas da represa e rios caudalosos);

- consagraram uma rota entre planalto e litoral que não passa pelos campos; inclusive, a cobrança de "pedágio" de andarilhos "brancos" a fazerem esse percurso, uma fonte de "renda";

- conservaram estreitos laços com a população "branca", para comércio e serviços (na Barragem há urbanização consolidada);

- cana, banana, milho, feijão, arroz, raízes e caça e pesca, são apontados por Ladeira (1984) como os recursos alimentares desses grupos.

Em estudo realizado por Luz (1998) sobre o uso de plantas medicinais pela população indígena da aldeia do Morro da Saudade, o autor constatou um pequeno número de espécies utilizadas (26). Muitas das espécies referidas são ruderais e mesmo exóticas, não havendo nenhuma tipicamente campestre. Ainda que em estudos etnobotânicos se deva considerar a possibilidade de subnotificação das espécies utilizadas, o autor tomou os cuidados exigidos 
por estudos desta natureza, como convivência prévia com a população local. Finalmente, o autor ressaltou a semelhança dos resultados obtidos com outros estudos realizados na região de Parelheiros e Santo Amaro.

Dessa forma, parece improvável que os campos tenham existência condicionada por práticas da população indígena local.

\section{Contexto Histórico-Geográfico Regional: Santo Amaro e Itanhaém}

Segundo Berardi (1981), a vila de Santo Amaro foi fundada em 1560, em "região de relevo brando com lindas e extensas campinas". O município de Santo Amaro ficou autônomo de São Paulo até 1935. Na época colonial era conhecido como o celeiro da capital, contudo, a autora não fez referência à extensão das áreas cultivadas. Também não fez nenhuma referência à região do Núcleo Curucutu, a não ser indiretamente, pelo fato de o limite do então município de Santo Amaro ser, ao sul, a crista da Serra do Mar. Ligações com o litoral de Itanhaém não foram consideradas importantes para a história do bairro, uma vez que não foram citadas. Conclui-se que o impacto antrópico, até a construção das represas no início do século XX, tenha sido pontual e pequeno, dada a grande extensão do município, a baixa densidade demográfica e a precariedade das vias de comunicação.

Quanto à questão do abastecimento, nota-se em Passaglia (1978) que o palmito foi um importante item de comercialização no mercado de Santo Amaro, ainda no final do século XIX, tanto que constava de tabelas oficiais de preços. $\bigcirc$ extrativismo da madeira, naquela época, era tão importante que havia uma política de realização de feiras de madeira para garantir compradores de São Paulo e mesmo a manutenção da ligação ferroviária com a capital. Não constam em Passaglia (1978) produtos resultantes de extrativismo de formações campestres. Contudo, a criação de gado deve ter exercido pressão sobre os campos, possivelmente os dos arredores da vila.

Quanto aos caminhos, encontrou-se nos relatórios da Comissão Geographica e Geologica do Estado de São Paulo (1920) sobre o litoral sul, baseado em levantamento de 1914, o primeiro registro em mapa do "Caminho para Santo Amaro", ligação do rio Branco ao planalto, bastante similar ao traçado da trilha atual do Núcleo Curucutu, que desce em direção ao rio Branco. Essa ligação também está assinalada na Carta dos excursionistas, produzida pela Comissão Geographica e Geologica (1923), passando pela localidade "Ponte Alta" em direção ao sul, até o paralelo 24S, parecendo aproximar-se do traçado da atual estrada de acesso ao núcleo.

Contudo, em mapa do município de Santo Amaro, apresentado por Caldeira (1935), não há registro de nenhum caminho em direção à atual sede do Núcleo Curucutu. Os dois caminhos mais longos em direção ao sul são: de 
Embura em direção W-SW, passando por Joaquim da Luz e daí para Itanhaém (atualmente Embu-Guaçu); e o outro passando por Varginha (próximo ao atual limite com São Bernardo do Campo, seguindo reto em direção S até João Rocumback (provavelmente próximo de Evangelista de Souza).

Petrone (1965), ao discutir as relações entre a Baixada Santista e a cidade de São Paulo, desde o início da colonização, realçou a importância do eixo Santos - São Paulo, via Cubatão, e a importância, no trecho de planalto, de eixo radial sudeste, consagrado pela via Anchieta. Foram registradas como variantes no trecho de planalto, no quinhentismo e no setecentismo, as rotas fluviais dos rios Pequeno, Grande e Pinheiros, até Santo Amaro ou Pinheiros. Tais rotas se estabeleceram, segundo o autor, devido à difícil travessia de extensa área brejosa ao longo desses rios, atualmente submersas, em grande parte, na represa Billings. Quanto a caminhos alternativos, o autor considerou importantes aqueles que surgiram no ciclo do ouro, ligando o Vale do Paraíba a alguns portos do litoral norte paulista. Contudo, como medida de controle proibiu-se, naquela época, a utilização de outros caminhos, em favor da ligação São Paulo - Cubatão - Santos. Assim, o autor não citou nenhuma ligação Santo Amaro - Itanhaém.

Zenha (1977), ao descrever os caminhos do período colonial que partiam de Santo Amaro, listou a ligação com Itanhaém, passando por Rio Bonito, Varginha, Cocaia, Colônia, Embura, até o Alto da Serra, "nos campos que ali se espraiam". Descida a serra, chegava-se ao Porto Velho, no rio Branco, de onde se prosseguia o caminho por barco até Itanhaém (Mapa 2). Esses caminhos coloniais aproveitaram trilhas indígenas. É bastante sugestivo que os funcionários do Núcleo Curucutu ainda utilizem e conheçam o caminho de descida da serra, o qual parte do núcleo como "trilha dos jesuítas", e a mesma termine no rio Branco, em um local conhecido como "Porto Velho". Em outro trecho o autor citou que o caminho Santo Amaro - Itanhaém foi utilizado, precariamente e por pouco tempo, em substituição ao Caminho do Mar (São Bernardo - Cubatão) que se encontrava fechado (provavelmente para manutenção) no governo de Rodrigo César de Menezes (século XVIII).

Em estudo de Gonçalves (1998), sobre o traçado do Peabirú, há discussão sobre um documento anterior a 1788, no qual registrava os antigos caminhos da Serra do Mar que ligavam São Paulo ao litoral, constando, ao sul, a ligação entre Itanhaém e Santo Amaro.

Segundo Zenha (1977), a vila de Santo Amaro se encontrava em área de fisionomia campestre ("campinas"), sendo "boca do sertão" no período do bandeirismo, também conhecida como Santo Amaro da Borda do Campo. Esses campos, contínuos aos de Piratininga (São Paulo), estavam separados dos campos do Alto da Serra, tendo em vista que a designação "Sertões de Santo Amaro" se referia a formações florestais densas, durante séculos 
utilizadas para extração de madeira, lenha e carvão, os quais abasteceram a capital.

Araújo Filho (1951) realizou um estudo sobre a ocupação humana na baixada do rio Itanhaém, aproximadamente correspondendo ao município homônimo, Mongaguá, e parte de Peruíbe. $\bigcirc$ autor ressaltou que essa parte do litoral paulista teve uma importância irrisória no desenvolvimento do estado, desde tempos coloniais, apesar de ter sido capital da Capitania de São Vicente, no início da colonização. Entre as causas para o isolamento e estagnação da área, o autor sugeriu as condições difíceis para instalação humana, devido à insalubridade local, aliada à escassez de água potável e, ainda, o paredão da Serra de Paranapiacaba, "num de seus pontos de mais difícil acesso". A comunicação com o resto do estado estabelecia-se, preponderantemente, por intermédio de Santos, com acesso marítimo ou pela praia.

A ligação com Santo Amaro, contudo, foi reconhecida e constava no mapa apresentado por Araújo Filho (1951), com a citação "simples picada". Esse caminho está assinalado partindo do rio Branco em sentido norte, paralelo ao espigão da serra de Mongaguá. Em seu trabalho não há qualquer comentário sobre a comunicação com Santo Amaro, a qual deve ter sido de mínima expressão, o que está de acordo com o discutido acima para Santo Amaro.

Dentre os tipos humanos e suas relações com o meio, reconhecidos por Araújo Filho (1951), os seguintes são importantes para a relação com a conservação da vegetação do planalto:

- $O$ pirangueiro, que vivia à margem dos rios, com caça, pesca e extrativismo para confecção de artesanato. Poderia realizar, eventualmente, deslocamentos maiores, subindo a serra à cata de plantas;

- lenhadores e carvoeiros. Ação importante para instalação e manutenção da estrada de ferro para Santos, mas de pouca importância no contexto estadual e aproveitada, sobretudo, pela bananicultura. $\bigcirc$ autor ressaltou a importância desse grupo durante a Segunda Guerra, especialmente sobre as matas da escarpa nos altos cursos dos rios Mambu e Branco.

No estudo de Langenbuch (1971), sobre o processo de metropolização da cidade de São Paulo, caracterizou-se o período de pré-metropolização, estendendo-se até cerca de 1875, em que a região da Serra do Mar era considerada zona desabitada; seguindo-se, em direção à cidade, um "cinturão caipira" no qual se praticava a agricultura de subsistência e o extrativismo vegetal, voltados ao abastecimento da capital. Dentre os caminhos que partiam de São Paulo, aqueles que demandavam ao sul saíam por Pinheiros - Cotia e não por Santo Amaro; a ligação com Itanhaém não foi citada, pois deve ter perdido importância muito cedo pela priorização do Caminho do Mar (São Bernardo - Cubatão). O autor citou, contudo, a existência de muitos caminhos secundários areolares. 
O período entre 1875 a 1940 foi marcado pela expansão urbana, impulsionada pela implantação da malha ferroviária (LANGENBUCH, 1971). Para a área do presente estudo, a linha ferroviária mais próxima é a Mayrink - Santos, completada em 1935, que não foi considerada como indutora de urbanização pelo autor, por ser apenas tangencial aos arredores paulistanos e não-radial, como as demais. No final do século XIX, Santo Amaro perdia importância, como produtor de madeira e lenha, para outras localidades servidas pelas ferrovias que passavam pela capital. Nesse período foi construída a represa Guarapiranga, e Santo Amaro passou a reforçar uma tendência de função recreativa para a capital; além disso, é anexado ao município da capital. Ao final desse período já se registrava a expansão da especulação imobiliária para chácaras de recreio e a estruturação do "cinturão verde" de abastecimento da capital; no caso de Santo Amaro, destacando-se a cultura de plantas ornamentais e frutas.

Segundo Langenbuch (1971), a partir da década de 1940 acentuou-se a metropolização e, nos arredores rurais, a substituição das matas naturais por eucaliptais, destacando que, em 1960, estes ocupavam área 70 vezes maior da ocupada em 1937/1938. Na década de 1950 ocorria um grande incremento na especulação imobiliária de chácaras recreativas, citando, como exemplo extremo, o loteamento Belvedere, no bairro rural de Santa Rita, vários quilômetros ao sul de Embu-Guaçu, às margens do rio Juquiá. As chácaras recreativas em Embu-Guaçu e Cipó atendiam, principalmente, à população da Baixada Santista, devido à ligação ferroviária. Na década de 1960 destacava-se, como nova forma de ocupação, a criação de clubes de campo.

Langenbuch (1971) concluiu agrupando os subúrbios rurais como "cinturão suburbano periférico", por manterem características rurais, mas em nítida relação com a metrópole. Parelheiros, com outros distritos, foi destacado na função de recreação campestre. Entre os tipos de uso de solo caracterizados para o cinturão encontra-se a categoria "reservas florestais", embora não tenha sido citado o Parque da Serra do Mar, mas apenas para os distritos de Paranapiacaba e Riacho Grande. $\bigcirc$ Núcleo Curucutu não foi citado (nem os correspondentes distrito de Parelheiros e o município de Juquitiba), apesar de já ter sido criado nessa época. $\bigcirc$ autor reconheceu a persistência (até a década de 1960) de atividades residuais de tempos pré-metropolitanos, como a agricultura caipira e a extração de lenha e madeira de matas naturais e capoeiras, apenas em São Lourenço da Serra, Caucaia do Alto e Santana de Parnaíba. Isso ilustra o que o autor considerou movimento centrífugo de atividades agrícolas em decorrência da especulação imobiliária e urbanização.

No mapa fitogeográfico para a região metropolitana apresentado por Hueck (1956), no qual destacou as atividades humanas como modificadoras da 
vegetação original, nota-se que grande parte da região teve a substituição da mata de planalto por "campos limpos e sujos, com alguns arbustos e restos de mata" e eucaliptais. Também reconheceu "florestas degeneradas contendo capoeiras", especialmente acompanhando as serras da Cantareira, de Paranapiacaba e do Mar. Foram ainda pontuadas as áreas com culturas agrícolas, como milho, e aquelas de "produção de carvão vegetal". Quanto a estas últimas há registro maior para o interior e borda das "florestas degeneradas" ao norte da Serra da Cantareira e na face interiorana das serras do Mar e de Paranapiacaba, especialmente nesta última, inclusive à altura da atual sede do Núcleo Curucutu.

Essa indicação pode ser constatada em algumas trilhas do local, onde há fornos (Foto 2) ou seus vestígios, como escavações típicas e carvão no solo (Foto 3). Também atestam essa atividade as ruas abertas na área campestre, atualmente reconhecíveis pelos cortes do terreno. Outro indicador da atividade carvoeira pode ser observado a partir da análise de diagramas polínicos (GARCIA, 2003), nos quais foi detectado carvão próximo à superfície. Contudo, Hueck (1956) não caracterizou a faixa campestre do núcleo como "campos limpos...", e sim

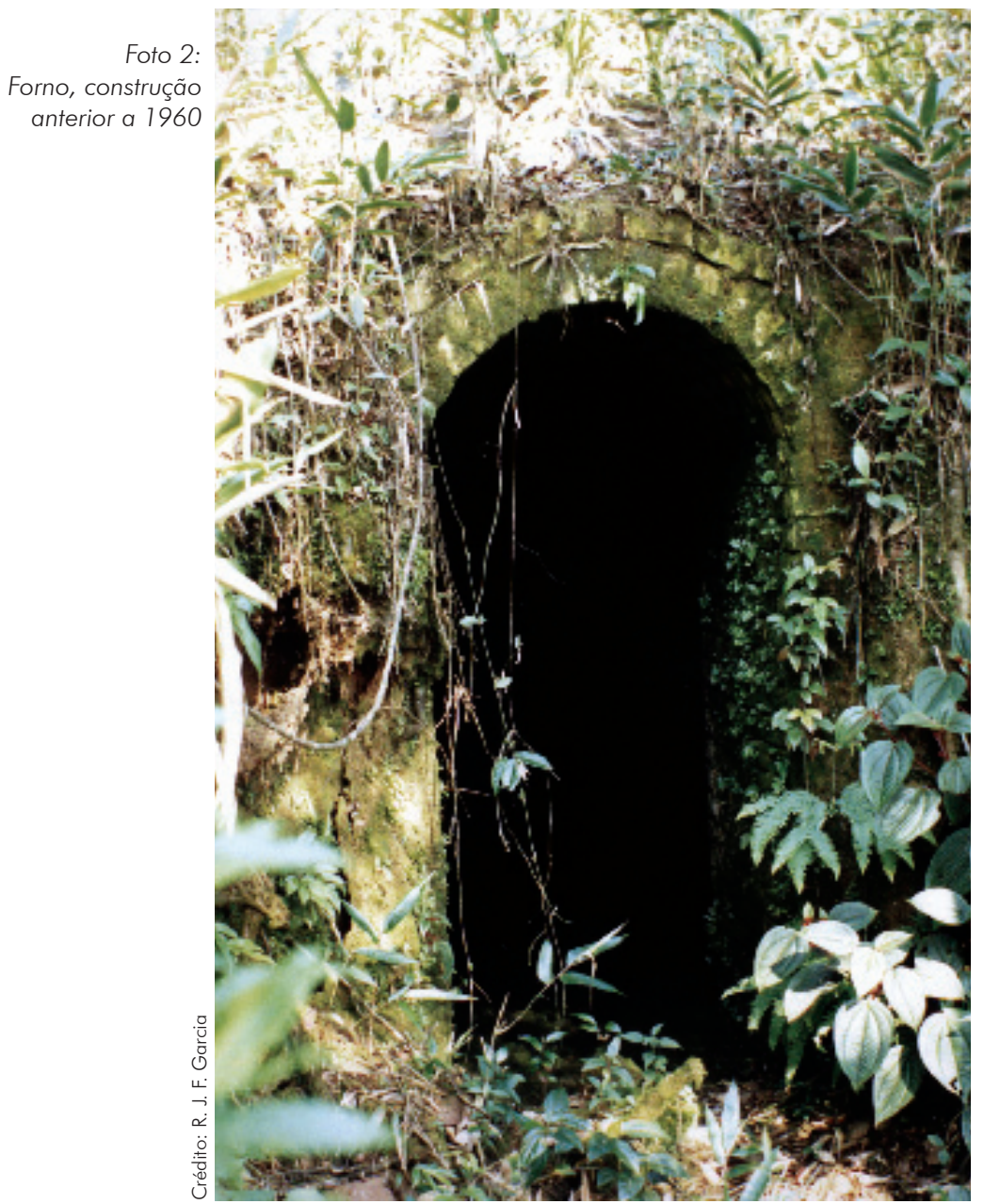
como "matas degeneradas", apesar da possibilidade de detectá-la na escala adotada no mapa.

A partir da década de 1970 destaca-se a lei de proteção aos mananciais de 1976, a qual objetivava garantir usos do solo compatíveis com a manutenção da qualidade da água das represas Billings e Guarapiranga, mas que, em grande parte, teve efeito contrário, pois o caráter altamente restritivo da lei, sem a devida fiscalização, propiciou a proliferação de ocupações irregulares. Outros aspectos atuais, que podem vir a comprometer a integridade física da área de estudo, foram discutidos em Garcia (2003). 


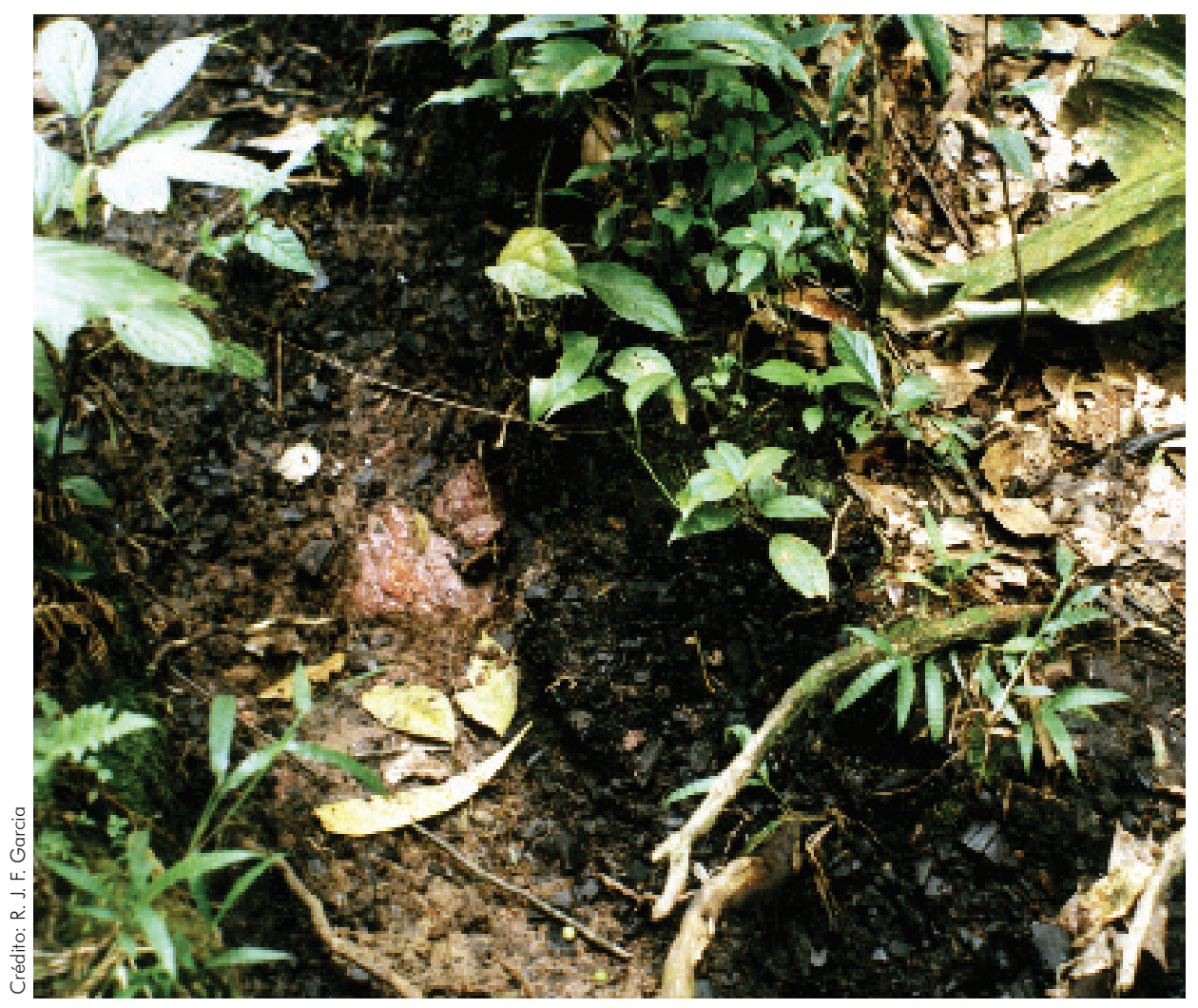

Foto 3:

Carvão no solo

\section{O Núcleo Curucutu}

Segundo Nogueira (2001), o Núcleo Curucutu do Parque Estadual da Serra do Mar, administrado pelo Instituto Florestal, originou-se como reserva florestal do estado, com 12.090 ha, pelo Decreto Estadual n. 36544/60, a partir da aquisição da Fazenda Curucutu, produtora de carvão.

No cadastro da vegetação significativa (SÃO PAULO, 1988), o Núcleo Curucutu contou com apresentação muito superficial, desatualizada e com incorreções. Por exemplo, quanto a elementos florísticos, a obra ressaltou a ocorrência de sapé, o que levou a inferir, pela origem antrópica desses campos, ocorrência não confirmada no levantamento florístico de Garcia (2003).

A partir do relato dos funcionários do núcleo quanto às possíveis intervenções antrópicas que poderiam ser consideradas como associadas à presença $\mathrm{e}$ manutenção dos campos, destacou-se haver pequenos eventos considerados significativos nos últimos 40 anos. Por exemplo, somente dois incêndios foram lembrados pelos funcionários: um ocorrido em 1993, em área contígua ao vizinho, de forma provocada e bastante localizada; e outro em 2001, de extensão considerável sobre os campos, provocado pela queda de um balão (Foto 4). Verificou-se, ainda, que a pressão de pastejo não foi significativa no período. 


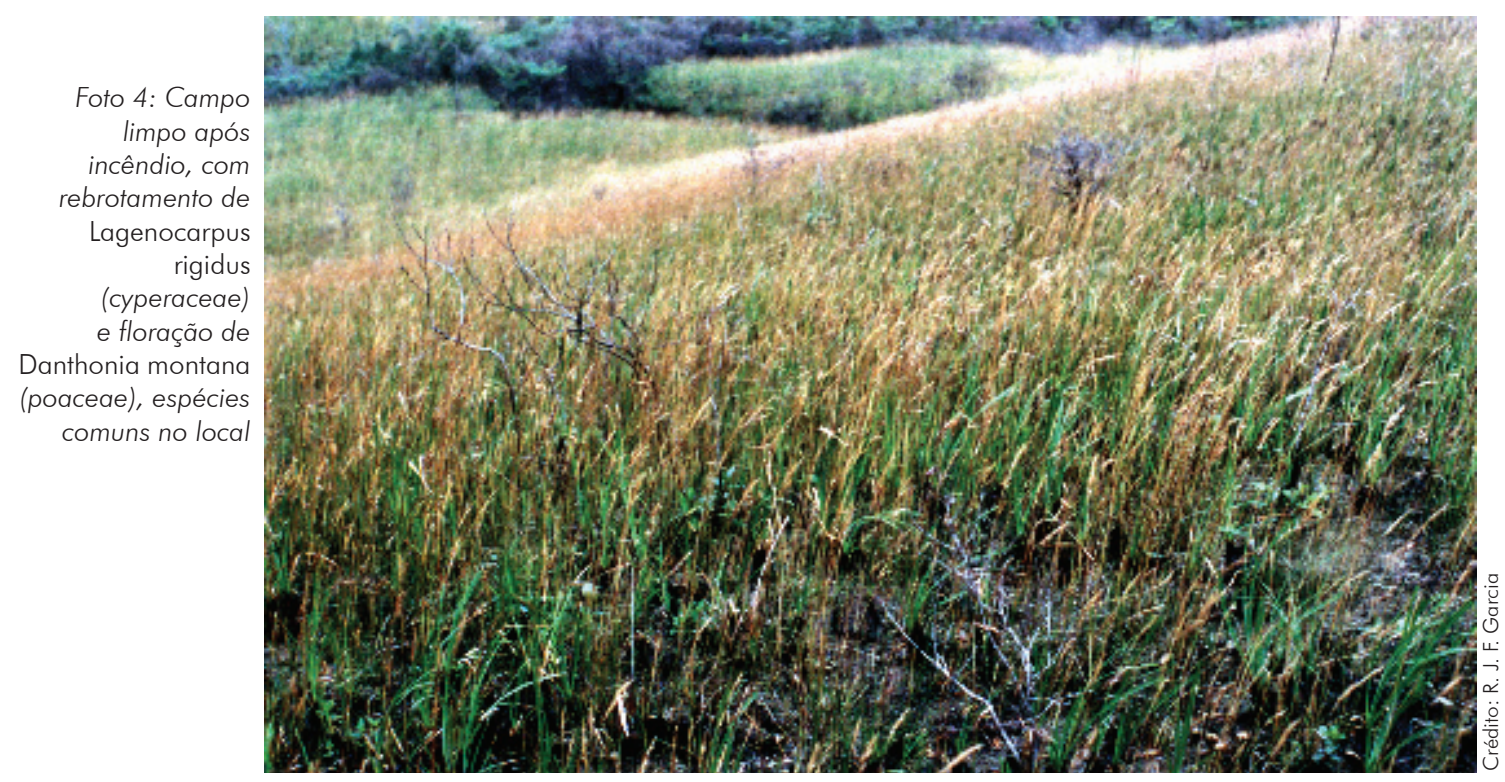

\section{Consulta a Exsicatas}

Realizou-se consulta aos herbários públicos no município de São Paulo (ver Mapa 2) ${ }^{1}$ a fim de realizar-se levantamento sobre as exsicatas ${ }^{2}$ de espécies campestres, ocorrentes no Núcleo Curucutu, que tivessem registro em outras áreas do município.

De 222 espécies registradas nos campos do Núcleo Curucutu (Fotos 5, 6, 7), apenas 41 também foram registradas em outros locais do município de São Paulo (GARCIA, 2003). Isso reforça a pequena similaridade encontrada entre os campos da Serra do Mar e os da bacia de São Paulo.

Apesar dos vieses de representatividade na listagem obtida, inerentes à metodologia, ressalta-se que a maior quantidade de registros refere-se ao período entre 1901 e 1950 (222 registros), seguido do período entre 1951 e 2000 (105). O período até 1900 apresentou apenas cinco registros, corroborando as considerações históricas apresentadas adiante.

Os dados ilustraram ainda a ubiqüidade dos campos no município de São Paulo, em áreas hoje urbanizadas, como Congonhas (região do aeroporto homônimo), Brooklin, Butantã, Jabaquara, Jaraguá, Ipiranga, Mooca, Santo Amaro, várzea do Tietê, Vila Mariana, entre outras (ver Mapa 2). Ressalta-se, ainda, que menos de 15\% das espécies levantadas tiveram registro maior no período mais recente, ilustrando o impacto da urbanização sobre a flora campestre.

(1) PMSP - Prefeitura do Município de São Paulo; SP - Instituto de Botânica; SPF - Instituto de Biociências da USP; SPSF - Instituto Florestal.

(2) Exsicata é uma amostra de planta submetida a um processo de secagem, montagem, identificação e catalogação em um herbário. 


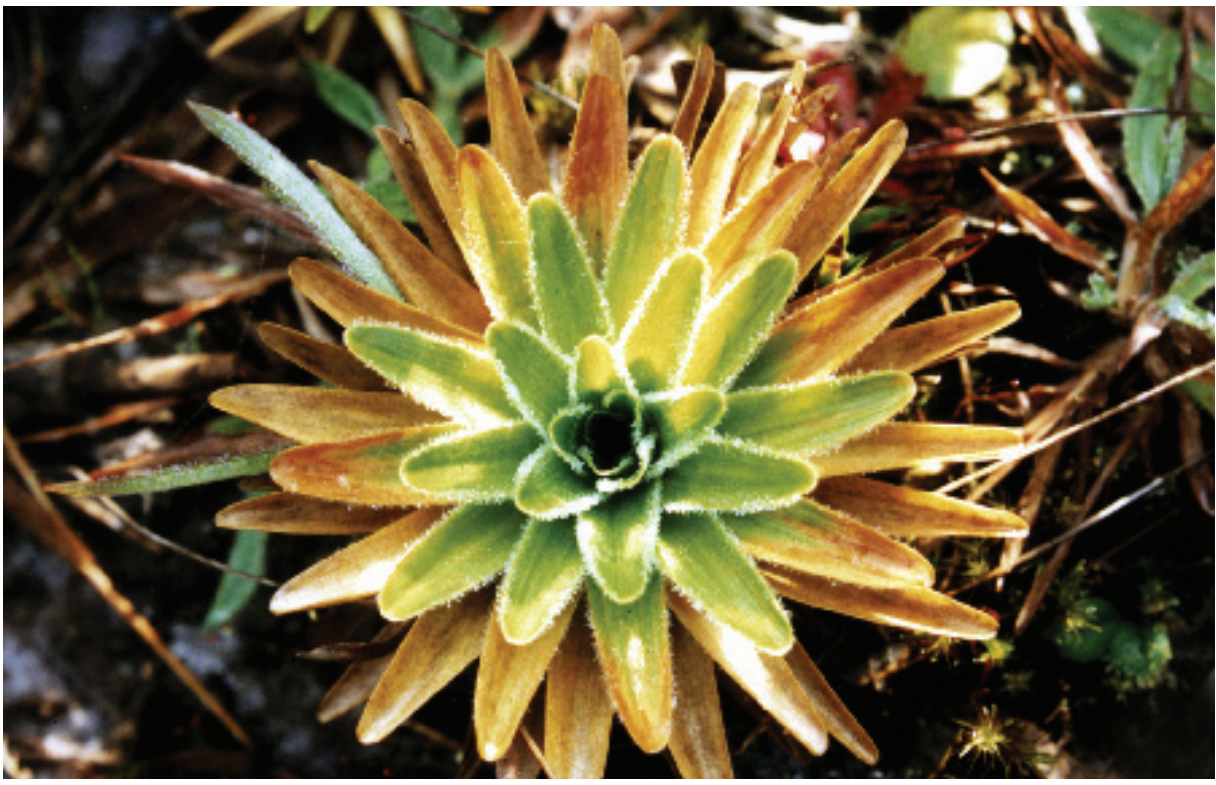

Foto 5: Leiothrix

flavescens

(eriocaulaceae),

espécie comum no local
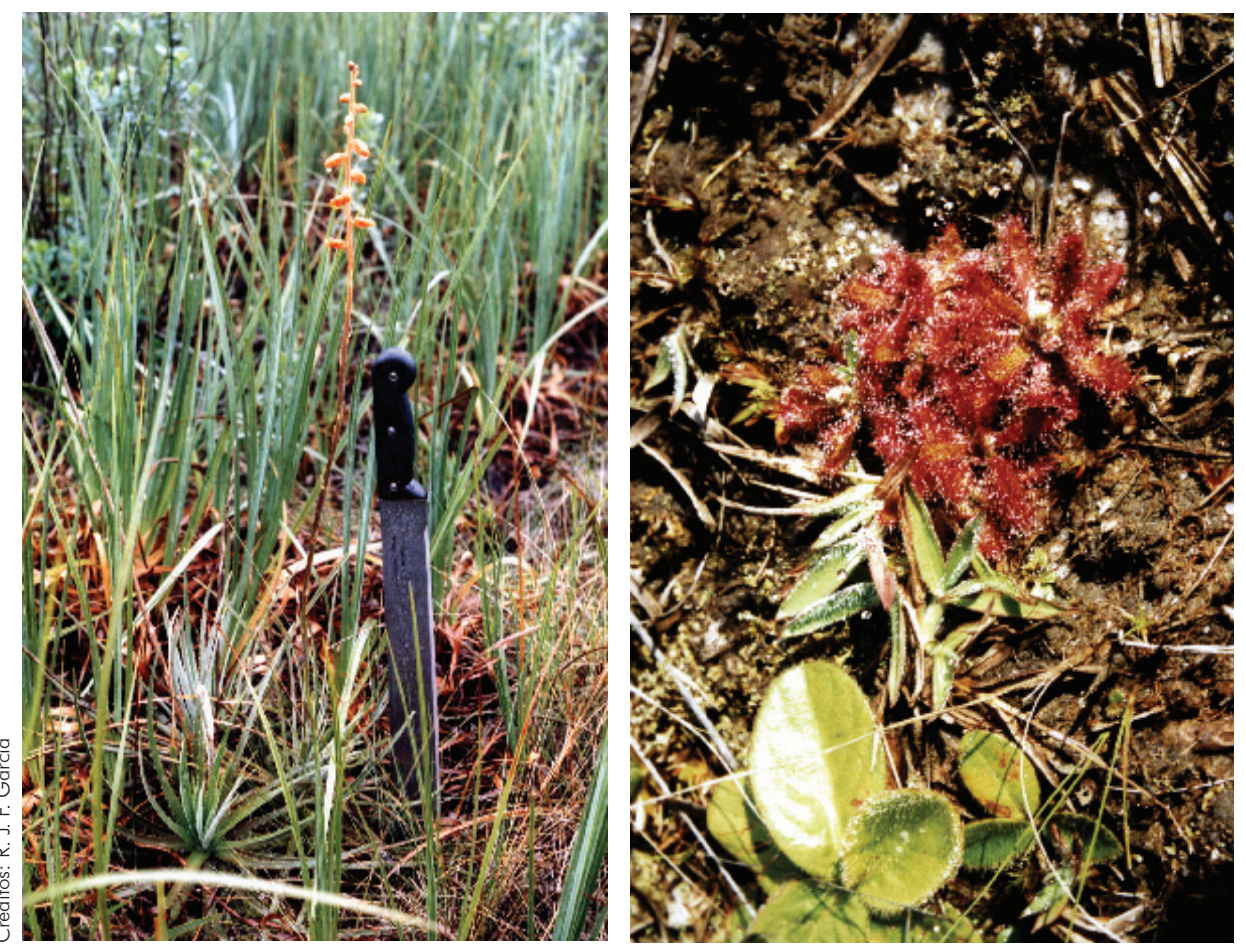

Foto 6: Richterago radiata

(asteraceae),

à esquerda, e

Drosera villosa

(droseraceae), à

direita, espécies comuns no local

\section{A Importância do Conhecimento da Flora para a Análise Histórica da Paisagem}

A seguir são apontadas algumas observações visando buscar explicações para o desconhecimento florístico do Núcleo Curucutu. Revisões e comentários históricos sobre o conhecimento da vegetação, no estado de São Paulo, podem ser encontrados em Mantovani (1993). 
Pode-se aqui reconhecer três fases sobre o estudo da flora paulistana, a partir da abertura do Brasil à comunidade científica internacional, no século XIX:

\section{Fase 1: Século XIX}

Ao resgatar informações na Flora brasiliensis sobre os coletores que contribuíram para essa obra e seus respectivos itinerários (URBAN, 1906), encontra-se 37 pesquisadores, em sua maioria europeus, os quais passaram pelo estado de São Paulo, muitas vezes utilizado como porta de penetração para o interior brasileiro. Desses, ao menos 24 passaram pela cidade ou arredores de São Paulo, provenientes, principalmente, de Santos, subindo a serra pelo Caminho do Mar (via Cubatão - São Bernardo), ou ainda provenientes do Vale do Paraíba, via Mogi da Cruzes e Penha, de onde já se avistava a cidade, devido à fisionomia campestre. A maioria das coletas então realizadas foram depositadas em herbários estrangeiros. Os coletores desse período, cujas plantas têm exsicatas nos herbários públicos paulistanos, são: Gustav Edwall, Albert Löfgren, Arsène Puttemans, nomes associados à coleção da Comissão Geográfica e Geológica do Estado de São Paulo, valioso acervo do Herbário SP. Além dos supracitados, destacam-se, como coletores que se demoraram um pouco mais nos arredores paulistanos, freqüentemente citando-se como pontos de interesse a Penha, o Morro do Jaraguá e a Serra da Cantareira: Auguste François Marie Glaziou, Antoine Guillemin, Karl Friedrich Philipp von Martius, Ludwig Riedel, Friedrich Sellow e Richard Wettstein Ritter von Westersheim. Este último coletor, segundo Urban (1906), foi o que mais excursionou pelos atuais arredores ao sul e sudoeste da capital, como Itapecerica, Santo Amaro e São Lourenço, além de ter percorrido a região de Itanhaém, especialmente os rios Branco e o Mambu. É esse autor, além de Löfgren, quem produziu uma das mais ricas descrições sobre a vegetação litorânea e a mata atlântica paulista do período.

Pelo que se depreende do período, campos associados à Serra do Mar só foram detectados na região de Paranapiacaba - Campo Grande, até porque se encontravam no percurso litoral - capital.

\section{Fase 2: início em meados do século XX}

Nota-se a estruturação de setores em instituições públicas atuantes na área de botânica, com seus respectivos herbários e hortos ou viveiros, ligados, inicialmente, a serviços de agricultura e saúde (MAMEDE, 1999). Posteriormente, tais órgãos passaram por mudanças administrativas diversas, gerando as atuais instituições de ensino e pesquisa, com os seguintes herbários:

- Herbário da Escola Politécnica, referente à coleção de A. Usteri, dos arredores da cidade (USTERI, 1911), que resultou na única publicação até o presente sobre a flora do município. Essa coleção foi, posteriormente, incorporada ao Herbário SP; 
- Herbário SP: iniciado em 1917, na Seção de Botânica, no Instituto Butantã; transferido para o Museu Paulista, depois para o Instituto Biológico; e, na década de 1930, para a Água Funda (Parque Estadual das Fontes do Ipiranga) com a criação do Instituto de Botânica;

- Herbário SPF: iniciado em 1932, na Faculdade de Farmácia e Odontologia, depois transferido para o Departamento de Botânica da Faculdade de Filosofia, Ciências e Letras da Universidade de São Paulo; atual Instituto de Biociências da USP;

- Herbário SPSF: iniciado em 1935, a partir do Serviço Florestal, sediado na Serra da Cantareira, com respectivo jardim botânico (atual Horto Florestal), hoje Instituto Florestal.

Como observado na análise de exsicatas, há diversas coletas na área do atual centro expandido da cidade, especialmente nos arredores de cada instituição. Considerando que a explosão de urbanização ocorreu a partir da década de 1940, as áreas coletadas ainda podiam ser consideradas "pouco antropizadas".

\section{Fase 3: a partir de meados do século XX}

Trata-se do período pós-metropolização, destacando-se as seguintes atividades:

- Realização de estudos científicos, principalmente a partir da década de 1980 (dissertações de mestrado e teses de doutorado), sobre as floras locais de remanescentes de vegetação, especialmente os florestais. Dados sobre a flora campestre encontram-se, basicamente, em Joly (1950), sobre os campos do Butantã; em Dorado (1992), com uma listagem preliminar da várzea do Parque Ecológico do Tietê, e em Garcia (2003) sobre os campos do Núcleo Curucutu;

- Início do Herbário PMSP, do Departamento de Parques e Áreas Verdes da Prefeitura do Município de São Paulo (1984), com atuação, inicialmente, voltada a atividades de divulgação e educação ambiental;

- Aumento de coletas, na década de 1990, especialmente na região sul do município, em remanescentes de vegetação, relativamente bem conservados, por intermédio dos projetos "Flora Fanerogâmica do Estado de São Paulo" e "Guarapiranga";

- Realização de estudos científicos em remanescentes de vegetação, por instituições de outras cidades (por exemplo, Unesp - Rio Claro, no Sesc Interlagos);

- Disponibilização, em meio digital, de banco de dados com informações sobre a flora do município (SÃO PAULO, 2004). 
A partir do exposto, destaca-se que o trabalho de Usteri (1911), apesar de ser o único a abordar de maneira mais abrangente a flora do município (então geograficamente menor que a área atual), acabou tendo pequena repercussão enquanto linha de pesquisa e, possivelmente, tenha sido pouco conhecido pela população, inclusive por estar escrito em alemão e latim. Infelizmente, também não foi considerado para o estabelecimento de uma política de conservação ambiental, de modo a não haver remanescentes atuais dos campos ora determinantes da paisagem paulistana, nem projetos que visem a este resgate histórico.

Outro aspecto a chamar a atenção é que a população do município de Santo Amaro não chegou a valorizar a flora e vegetação local, para fins científicos ou artísticos, por exemplo. Assim, no Album de Santo Amaro, de Caldeira (1935), pouco posterior ao primeiro centenário do município, não há exaltação dos atributos naturais da região, nem documentação sobre o assunto (se existente). Isso deve ser destacado por alguns motivos:

- Segundo Langenbuch (1971), o município foi, durante muito tempo, uma opção de lazer dos paulistanos, mesmo antes da construção das represas, devido ao aspecto pitoresco da região;

- aparentemente, o histórico de ocupação alemã na região não chegou a produzir trabalhos (conhecidos atualmente) sobre a flora local, tampouco resultou em núcleos de investigação locais ou despertou intercâmbios com pesquisadores patrícios, como sucedido em outros núcleos de colonização alemã no Brasil. Chama a atenção, por exemplo, que as coletas de von Wettstein na região (URBAN, 1906) não constem nesse álbum. É certo que existiram outros coletores na região, como atestam exsicatas do Herbário SP, contudo não geraram nenhum trabalho científico publicado no Brasil;

- As poucas fotos que ilustram matas, assim o fazem para valorizar propriedades rurais quanto aos recursos extrativos (para as respectivas serrarias, por exemplo).

Também não deixa de ser, no mínimo, curioso, que na época de Frederico Carlos Hoehne e Moisés Kuhlmann, os quais empreenderam longas excursões por São Paulo e estados vizinhos, haja poucos registros de coleta do Instituto de Botânica para a região de Santo Amaro, com a exceção da área contígua a São Paulo, como Jabaquara e os "campos de Congonhas", onde, atualmente, encontra-se o Aeroporto de Congonhas. Pelo menos não se encontram sistematizados nas publicações do instituto.

A informação botânica prévia sobre o Núcleo Curucutu também é escassa. De coletas anteriores ao levantamento de Garcia (2003), somente duas foram encontradas, como "Santo Amaro - Fazenda Curucutu, campos pedregosos úmidos", de M. Kuhlmann, em 1950. Os locais mais próximos coletados 
anteriormente são a linha férrea Mayrink - Santos, na década de 1930, aproximadamente, e na planície litorânea, junto do rio Branco, no início do século $X X$, por Wettstein. Dessa forma, não é surpreendente que no núcleo tenham sido encontradas espécies novas e novas ocorrências para o estado (GARCIA, 2003).

Apesar da grande quantidade de coletas em áreas campestres paulistanas, anteriores ao período de metropolização, conforme análise de exsicatas, tais informações não foram sistematizadas em checklists, por exemplo, de forma que não há, ainda, nenhum trabalho publicado sobre o assunto. Isso, de certa maneira, também contribuiu para que não houvesse discussão sobre a criação de parques/reservas nessas áreas campestres. A conservação destas, mesmo nas instituições de pesquisa, foi deixada em segundo plano: pouco sobrou dos "campos de Butantã" na USP (mantidos apenas em uma parte dos jardins do Departamento de Botânica) e dos "campos cerrados" do Parque do Estado.

São escassos os exemplos de iniciativas de criação de parques a manterem ou recuperarem a vegetação campestre no município de São Paulo. Cita-se o Parque Cidade, de Toronto, e o Parque Ecológico do Guarapiranga, em que as áreas brejosas foram valorizadas nos respectivos projetos paisagísticos. Um exemplo emblemático da falta de interesse pelos campos é a praça do Relógio, na Cidade Universitária: na proposta de ilustrar os ecossistemas do estado não houve a preocupação de destinar um espaço para os "campos de Butantã", exatamente sobre os quais foi construído o campus. Em outro exemplo, Rocha \& Cavalheiro (2001) ressaltaram a inexistência de coleções de plantas características dos "campos de Piratininga", apesar de ser objetivo da criação do Jardim Botânico de São Paulo representar a flora local.

\section{Considerações Finais}

Os resultados obtidos reforçam a hipótese que os campos do Núcleo Curucutu são naturais e não de origem antrópica. Apesar de estar na rota entre Santo Amaro e Itanhaém, a área não registra sinais de ocupação humana. Ações antrópicas de maior impacto aparecem relacionadas ao período da atividade carvoeira, especialmente nas décadas de 1940/1950, que pode ter favorecido a ampliação da área campestre, pela retirada das árvores, bem como pela abertura de caminhos. Além disso, como a atividade carvoeira e a extração de madeira ocorreram de maneira generalizada no arco sudoeste - sul - sudeste - leste da Grande São Paulo (São Lourenço da Serra, Juquitiba, Parelheiros, Riacho Grande, Rio Grande da Serra, Mogi das Cruzes), seria de esperar-se fisionomias e floras similares às encontradas no Núcleo Curucutu, por toda esta região, caso a mesma fosse o produto desta atividade antrópica, o que não é observado. 
Não se registrou nenhum produto de extrativismo tipicamente campestre na atividade econômica (nem da atividade indígena) ou ainda referência à pecuária que justificassem a manutenção da área campestre em detrimento da área florestal, como poderia ser interpretado a partir do histórico da prática agrícola brasileira de roçadas com queimadas e itinerância de cultivo. Mesmo atualmente, as propriedades rurais da região, quando criam gado bovino, fazem-no em pequeno número e de modo extensivo nas áreas florestais.

Um aspecto importante a ser investigado é como a possível facilidade para ocupação humana (agricultura, pastoreio ou urbanização), oferecida pela vegetação campestre, associada a uma vulnerabilidade de proteção legal, facilitaram a ocupação dessas áreas sem mecanismos de reserva legal, como para as florestas. É sintomático que a legislação de proteção à vegetação (como a Lei n. 4.771, de 15 de setembro de 1965) seja conhecida como Código Florestal, e não Código da Cobertura Vegetal, por exemplo.

A partir da constatação da ubiqüidade dos campos na cidade de São Paulo e seu desaparecimento com a expansão urbana, torna-se necessário levar em conta sua existência para proposição de parques e reservas ou áreas para implantação de vegetação, e considere este elemento, de forma a resgatar um pouco da paisagem e flora da região. Os autores Rocha e Cavalheiro (2001) sugeriram, por exemplo, a criação de coleções de plantas características dos "campos de Piratininga" para ampliação da representatividade do Jardim Botânico de São Paulo. Nesse sentido, pode-se constatar a importância do Núcleo Curucutu como fonte de matrizes para programas de resgate histórico dessa flora.

\section{Bibliografia}

ARAÚJO FILHO, José Ribeiro de. A baixada do rio Itanhaém - Estudo de geografia regional. Boletim da Faculdade de Ciências e Letras da Universidade de São Paulo, Geografia, São Paulo, n. 5, p. 1-75, 1951.

AZEVEDO, Aroldo E. Pinheiros. Aspectos geográficos de um bairro paulistano. São Paulo: Edusp, 1963.

BERARDI, Maria Helena Petrillo. Santo Amaro. São Paulo: Prefeitura do Município de São Paulo - Secretaria Municipal da Cultura, 1981.

CALDEIRA, João Netto. Álbum de Santo Amaro. São Paulo: Organização Cruzeiro do Sul, 1935.

COMISSÃO GEOGRAPHICA E GEOLOGICA. Carta dos excursionistas - Primeira secção. São Paulo: Typogr. Brazil de Rothschild, Escala 1:200.000, 1923. 
COMISSÃO GEOGRAPHICA E GEOLOGICA DO ESTADO DE SÃO PAULO. Cidade de Santos à fronteira do Estado do Paraná. Exploração do Litoral, 2. Secção. São Paulo: Typogr. Brazil de Rothschild, 1920.

COUTINHO, Leopoldo Magno. Contribuição ao conhecimento da ecologia da mata pluvial tropical. Boletim da Faculdade de Ciências e Letras da Universidade de São Paulo, Botânica, São Paulo, n. 18, p. 7-219, 1962.

DORADO, Alejandro Jorge. Planificação ambiental no Parque Ecológico do Tietê, na Região Metropolitana de São Paulo. 1992. Dissertação (Mestrado) - Instituto de Biociências, Universidade de São Paulo, São Paulo, 1992.

GARCIA, Ricardo José Francischetti. Estudo florístico dos campos alto-montanos e matas nebulares do Parque Estadual da Serra do Mar - Núcleo Curucutu, São Paulo, SP, Brasil. 2003. 356 p. Tese (Doutorado) - Instituto de Biociências, Universidade de São Paulo, São Paulo, 2003.

GARCIA, Ricardo José Francischetti; PIRANI, José Rubens. Análise florística, ecológica e fitogeográfica do Núcleo Curucutu, Parque Estadual da Serra do Mar (São Paulo, SP), com ênfase nos campos junto à crista da Serra do Mar. Hoehnea, São Paulo, v. 32, n. 1, p. 1-48.

GONÇALVES, Daniel Issa. O Peabirú: Uma trilha indígena cruzando São Paulo. Cadernos de Pesquisa do LAP, São Paulo, n. 24, p. 4-74, 1998.

HOEHNE, Frederico Carlos. Album da Secção de Botânica do Museu Paulista e suas dependências, etc. São Paulo: Impr. Methodista Ed., 1925.

HUECK, Kurt. Mapa fitogeográfico do Estado de São Paulo. Boletim Paulista de Geografia, São Paulo, n. 22, p. 19-25, 1956.

JOLY, Aylthon Brandão. Estudo fitogeográfico dos campos de Butantã (São Paulo). Boletim da Faculdade de Ciências e Letras da Universidade de São Paulo, Botânica, São Paulo, n. 8, p. 5-67, 1950.

LADEIRA, Maria Inês Martins. Aldeias livres guarani do litoral de São Paulo e da periferia da capital. In: Índios no Estado de São Paulo: Resistência e transfiguração. São Paulo: Ed. Yankatu \& Comissão Pró-Índio de São Paulo, 1984.

LANGENBUCH, Juergen Richard. A estruturação da Grande São Paulo - Estudo de geografia urbana. Rio de Janeiro: Fundação IBGE, 1971.

LÖFGREN, Alberto. Ensaio para uma distribuição dos vegetaes nos diversos grupos floristicos no Estado de São Paulo. Boletim da Commissão Geographica e Geologica do Estado de São Paulo, São Paulo, n. 11, p. 1-50, 1898.

LUZ, Vanderlei Alves. Levantamento do uso de plantas medicinais utilizadas na Aldeia do Morro da Saudade - Município de São Paulo. 1998. 89 p. Monografia (Bacharelado) - Faculdade de Biologia, Universidade de Santo Amaro, São Paulo, 1998.

MAMEDE, Maria Cândida Henrique. Os herbários do estado de São Paulo. In: JOLY, C. A.; BICUDO, C. E. M. (Org.) Biodiversidade do estado de São Paulo - Síntese do conhecimento ao final do século XX. São Paulo: Fapesp, v. 7, p. 71-79, 1999.

MANTOVANI, Waldir. Estrutura e dinâmica da floresta atlântica na Juréia, Iguape - SP. 1993. 126 p. Tese (Livre-Docência) - Instituto de Biociências, Universidade de São Paulo, São Paulo, 1993. 
NOGUEIRA, Sílvia M. B. Análise da suscetibilidade ambiental e diretrizes para o zoneamento do Núcleo Curucutu do Parque Estadual da Serra do Mar (SP). 2001. 247p. Dissertação (Mestrado) - Instituto de Geociências e Ciências Exatas, Universidade Estadual Paulista, Rio Claro, 2001.

PASSAGLIA, Luiz Alberto do Prado. Mercado Velho de Santo Amaro. São Paulo: PMSP - Departamento do Patrimônio Histórico, 1978. (Série Registros).

PETRONE, Pasquale. Povoamento e caminhos nos séculos XVI e XVII. In: A Baixada Santista - Aspectos Geográficos, vol. II - Povoamento e População. São Paulo: Edusp, 1965.

ROCHA, Yuri Tavares; CAVALHEIRO, Felisberto. Aspectos históricos do Jardim Botânico de São Paulo. Revista Brasileira de Botânica, São Paulo, v. 24, n. 4, p. 577586, 2001.

SÃO PAULO (Cidade). Atlas ambiental do município de São Paulo - O verde, o território, o ser humano: Diagnóstico e bases para a definição de políticas públicas para as áreas verdes no município de São Paulo. São Paulo: Secretaria Municipal do Verde e do Meio Ambiente, 2004.

SÃO PAULO (Estado e Cidade). Vegetação significativa do município de São Paulo. São Paulo: Secretaria do Meio Ambiente \& Secretaria Municipal de Planejamento, 1988.

URBAN, Ignatius. Vitae itineraque collectorum botanicorum, notae collaboratum biographicae, florae brasiliensis ratio edendi chronologia, systema, index familiarum. In: MARTIUS, C. P. F.; EICHLER, A. G.; URBAN, I. (Ed.) Flora brasiliensis. Monachii: Typogr. Regia. v. 1, n. 1, p.1-268, 1906.

USTERI, Alfred. Flora der Umgebung von Stadt São Paulo in Brasilien. Jena: Verlag \& Gustav Ficher, 1911.

WETTSTEIN, Richard Ritter von. Plantas do Brasil - Aspectos da vegetação do Sul do Brasil. São Paulo: Ed. Edgard-Blücher / Edusp, 1970.

ZENHA, Edmundo. A Vila de Santo Amaro. São Paulo: Secretaria Municipal de Cultura - Departamento do Patrimônio Histórico, 1977. 